\title{
Atrioventricular block registration with smart phone associated ECG device.
}

Paweł Balsam ${ }^{1, \mathrm{~A}-\mathrm{F}}$, Monika Gawalko ${ }^{1, \mathrm{C}-\mathrm{D}}$, Piotr Lodziński ${ }^{1, \mathrm{~A}-\mathrm{F}}$, Marcin Grabowski ${ }^{1, \mathrm{~A}-\mathrm{F}}$, Łukasz Kołtowski ${ }^{1, \mathrm{~A}-\mathrm{F}}$, Michał Peller ${ }^{1, A-F}$, Grzegorz Opolski ${ }^{1, A-F}$

A - Research concept and design, B - Collection and/or assembly of data, C - Data analysis and interpretation,

D - Writing the article, E - Critical revision of the article, F - Final approval of article

1 1st Department of Cardiology, Medical University of Warsaw

Address for correspondence:

Paweł Balsam, 1st Department of Cardiology, Medical University of Warsaw email: pawel.balsam@me.com

Monika Gawalko, 1st Department of Cardiology, Medical University of Warsaw email: mongawalko@gmail.com

Piotr Lodziński, 1st Department of Cardiology, Medical University of Warsaw email: piotr.lodzinski@wum.edu.pl

Marcin Grabowski, 1st Department of Cardiology, Medical University of Warsaw email: grabowski.marcin@me.com

Łukasz Kołtowski, 1st Department of Cardiology, Medical University of Warsaw email: lukasz@koltowski.com

Michał Peller, 1st Department of Cardiology, Medical University of Warsaw email: michalpeller@gmail.com

Grzegorz Opolski, 1st Department of Cardiology, Medical University of Warsaw email: cardiology@wum.edu.pl

Received: 21.12.2016

Revised: 26.12.2016

Accepted: 27.12.2016

\section{Key words:}

\section{AliveCor ECG; electrocardiogram; 12-lead; smart phone ECG}

\section{Introduction}

The prevalence of cardiac rhythm disturbances increases with age and requires active screening for early detection. However, time, resources and costs are the main limiting factors for wider adoption of cardiac screening in the community setting. The ubiquitous access to the Internet and the dynamic adoption of smartphones provide opportunities for new technologies that transmit biomedical data, such as

\section{Case Report}

A 70-year-old woman with a history of hypertension (for one year) and exercise intolerance for 4 months was visiting a cardiologist, who performed a 1-lead ECG with smartphone application called Kardia (AliveCor, Inc.). Because of advanced second degree AV block with 2:1 and 3:1 the patient was referred to the hospital. At admission to the hospital the smartphone ECG and its interpretation were confirmed by
ECG. An example of such technology is Kardia Heart Monitor (AliveCor, Inc) that connects wirelessly to the smartphone and allows 30-second rhythm strips to be recorded. Pocket-size, mobile health devices provide an unprecedented opportunity for physicians to detect abnormalities in a quick and hassle-free fashion ${ }^{[1]}$.

standard 12-lead ECG. As is shown in Figure 1, no significant difference was noted between the two records. Both ECG tracings show sinus rhythm with atrioventricular block (3:1 and 2:1) with heart rate $48 \mathrm{bpm}$. Because of the advanced AV block, the decision to implant a permanent pacemaker was taken immediately. 


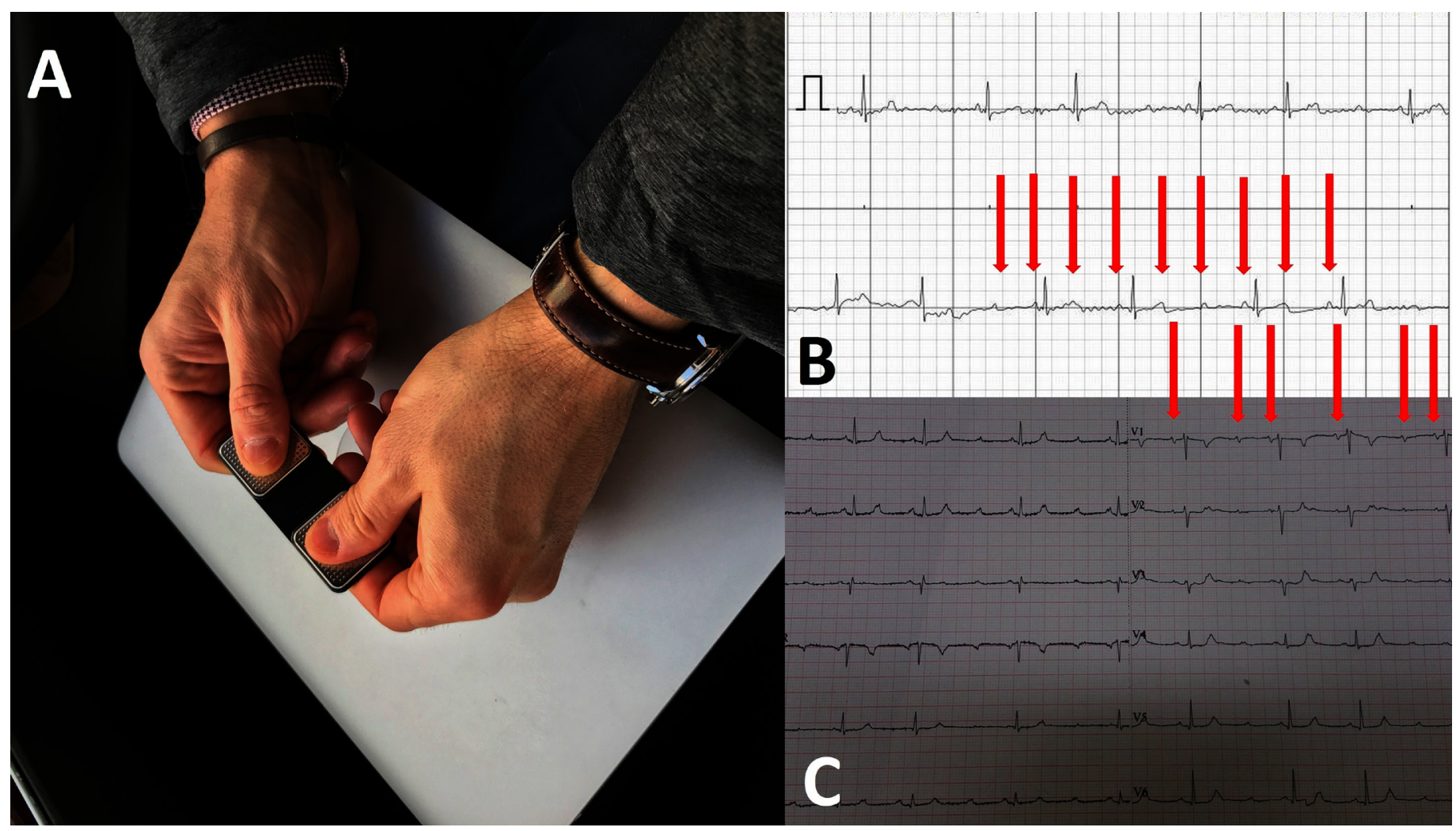

Figure 1 AliveCor's device (A) and generated ECG (B) corresponding to I lead of standard 12-lead ECG (C). P waves (red arrows).

\section{Case Report}

A 70-year-old woman with a history of hypertension (for one year) and exercise intolerance for 4 months was visiting a cardiologist, who performed a 1-lead ECG with smartphone application called Kardia (AliveCor, Inc.). Because of advanced second degree AV block with 2:1 and 3:1 the patient was referred to the hospital. At admission to the hospital the smartphone ECG and its interpretation were confirmed by standard 12-lead ECG. As is shown in Figure 1, no significant difference was noted between the two records. Both ECG tracings show sinus rhythm with atrioventricular block (3:1 and 2:1) with heart rate $48 \mathrm{bpm}$. Because of the advanced AV block, the decision to implant a permanent pacemaker was taken immediately.

\section{Conclusions}

Smartphone-based electrocardiography is a promising, developing technology intended to increase availability and speed of electrocardiographic evaluation ${ }^{[2]}$.This case confirms the potential of a smartphone ECG for evaluation of the $P$ waves and arrhythmias in comparison with a standard record. This device has an excellent correlation with the gold standard 12-lead ECG. The benefits of this technology for improving public awareness of health and for the early diagnosis of arrhythmias are significant ${ }^{[3]}$.

\section{References}

1. Baquero G. A, Banchs J.E, Ahmed S, Naccarelli G.V, Luck J.C. Surface 12 lead electrocardiogram recordings using smart phone technology. Journal of Electrocardiology 48(1). September 2014

2. Muhlestein JB, Le V, Albert D, Moreno FL, Anderson JL et al. Smartphone ECG for evaluation of STEMI: results of the ST LEUIS Pilot Study. Journal of Electrocardiology 48(2). March-April 2015

3. Saxon, L.A. Ubiquitous wireless ECG recording: powerful tool physicians should embrace. J Cardiovasc Electrophysiol. 2013;24:480-483. 